\title{
Cólera: um retrato permanente
}

\author{
Cholera: a permanent portrait
}

\author{
Claudio Bertolli Filho \\ Faculdade de Arquitetura, Artes e Comunicação e Faculdade de Ciências \\ da Universidade Estadual Paulista (UNESP) \\ Av. Nações Unidas, 45-30, ap. 12 B \\ 17033-260 Bauru - SP \\ cbertolli@uol.com.br
}

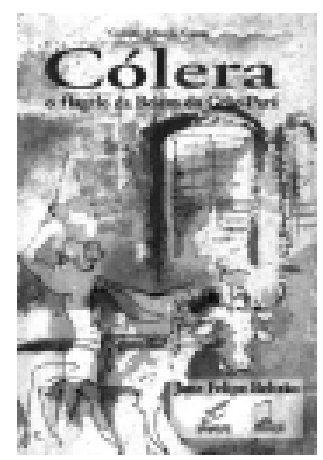

Jane Felipe Beltrão Cólera: o flagelo da Belém do Grão-Pará Belém, Museu Paraense Emílio Goeldi/ Universidade Federal do Pará, 2004, 354p. (Coleção Eduardo Galvão)
$\mathrm{N}$ os primeiros anos da década de 1990 uma epidemia de cólera grassou no Pará. Perante a ameaça, mobilizou-se o arsenal sanitário regional e, superado o desafio, a academia empenhou-se não só em explicar o ocorrido como também em (re)pensar a própria trajetória pretérita da enfermidade na região. Os resultados desta iniciativa foram objeto da pesquisa que resultou no livro de Jane Felipe Beltrão, que expõe a importância estratégica da história recorrente, isto é, de uma história explicitamente ancorada em uma problemática que incomoda por não estar confinada ao passado, mas que está aí, atuante e tragicamente ameaçadora.

Com tal encaminhamento, a obra em questão retira do ostracismo uma parcela do histórico sanitário de uma extensa região do país. Se já se conta com um número razoável de estudos históricos sobre a doença e a saúde especialmente no Sudeste brasileiro, ainda são raras as análises históricas acerca do perfil patológico da região Norte, circunstância que amplia o valor e significado da pesquisa realizada por Beltrão. O livro prima por focar de forma singular a epidemia de cólera, que, importada do Oriente e trazida por imigrantes portugueses da região do rio Douro, abateu-se sobre o Grão-Pará entre maio de 1855 e fevereiro de 1856, disseminando-se de imediato por outras áreas intensamente povoadas do litoral brasileiro.

Beltrão seguiu a epidemia desde a Europa, denunciando o estado de miséria que obrigava uma legião de portugueses a partir de suas regiões natais e o esforço das autoridades lusitanas em esconder a presença do mal do Ganges no seu território, a ponto de não impedir a saída da gente que vinha para o Brasil. Aqui, logo após a chegada dos lusitanos, a cólera apresentou os primeiros sinais devastadores, levando a comunidade médica paraense a se debruçar sobre a mortal ameaça. Em uma época em que, refletindo a tendência européia, os médicos brasileiros digladiavam-se na defesa dos pressupostos que defendiam os males de cunho epidêmico como resultado da infeção ou do contágio, o enigma da enfermidade ganhou contornos sombrios. Assim, enquanto o povo começava a morrer e os médicos debatiam os mecanismos de disseminação da doença - inicialmente desconhecidos - , no plano político e econômico as autoridades paraenses mostravam-se reticentes em assumir o estado pestífero, já que tal resolução implicaria a paralisação momentânea de muitos negócios provinciais. No mesmo enredo, se nada ou muito pouco foi realizado em defesa da população, pairava sobre os poderosos o receio de que 
o avanço da cólera favorecesse a ocorrência de um motim popular, que poderia colocar em questão a própria legitimidade do poder instituído.

A autora analisou a complexidade do dilema, com base nas matérias da imprensa local e nos compêndios médicos escritos nos anos seguintes à epidemia. Políticos e comerciantes mostravam-se temerosos tanto com o escamoteamento da enfermidade quanto com a declaração oficial da existência da peste. A comunidade médica debatia a identidade do mal, invocando inclusive a autoridade dos profissionais formados na Europa sobre os graduados no país, ao alegar que os óbitos ocorridos no navio que trouxera a cólera podiam ser conseqüência do envenenamento dos alimentos consumidos a bordo e dos maustratos impostos pela tripulação aos viajantes, e não de uma enfermidade que poderia se disseminar nesta parte da América. Quando o mal se espalhou por Belém e já se assumia a presença da cólera, também foi comum alegar que sua propagação se devia à não-observância, por parte da população, das regras básicas de higiene, atribuindo responsabilidade aos próprios habitantes da urbe pela doença que os assaltava.

Ao ser admitida a visita da cólera ao Pará, outro ponto de impasse explorado por Beltrão foi a medicação a ser utilizada contra a doença. A regra comum foi que cada médico indicasse uma terapêutica própria, multiplicando-se o número de opções medicamentosas e, com isto, aumentando a sensação de desamparo entre os carentes. Nesse compasso, a força da enfermidade e o aumento do número de infec-tados e mortos permitiram que outras vozes ganhassem destaque. Práticos homeopatas, curadores, benzedeiras e raizeiros saíram da semiclandestinidade para oferecer seus remédios, suas rezas e seus conselhos aos aflitos paraenses, compondo uma polifonia que tanto amparava quanto desorientava a população. Beltrão ressalta que, nesse contexto, a epidemia enfraqueceu momentaneamente a rígida hierarquia entre os profissionais da saúde, ganhando alento de salvadores tanto os médicos graduados em escolas médicas quanto os práticos e também os personagens que empregavam métodos populares de tratamento dos enfermos. Assim, pode-se ponderar que a crise sanitária não produziu o temido caos, mas favoreceu a reordenação dos saberes e poderes em prol do socorro popular.

Acompanhando a tendência registrada em outros estudos contextualizados em momentos epidêmicos, Beltrão destaca em sua obra as repercussões sociais da enfermidade no tecido coletivo, e nesta tarefa reside o principal mérito de sua obra. A fluência da cólera e o horror alimentado por uma doença que, segundo a pesquisadora, extingue a humanidade e 'animaliza' suas vítimas permitiram colocar em xeque a identidade dos habitantes da cidade de Belém. Neste processo ganhou curso uma análise que enquadrou a enfermidade e seus tributários na história local. Tipos humanos e estratégias de sobrevivência econômica adquiriram uma surpreendente coloração, irmanando solidariamente agrupamentos diversificados que, sadios, ofereciam de tudo um pouco para acudir as vítimas da peste e aqueles que, ao perderem quem os sustentava, careciam da ajuda pública para sobreviverem durante a quadra epidêmica.

Em um período em que os hospitais mostravam-se pessimamente equipados, assolados pela falta de medicamentos e pautados pela ausência 
de higiene, coube ao personagem comum — rico ou pobre - amparar os mais necessitados. O império da peste permitiu, assim, que seres anônimos ganhassem destaque, sem contudo merecerem homenagens posteriores. Em vez deles, perpetuaram-se na memória popular algumas 'vítimas ilustres' da cólera, destacando-se a figura de Ângelo Custódio Correa, presidente da província do Grão-Pará, que faleceu vitimado pela enfermidade quando, em companhia de familiares, foi levar pessoalmente alguma ajuda aos habitantes de Cametá, sua terra natal.

A morte em série, como não poderia deixar de ser em meados do século XIX, também foi interpretada pelo prisma religioso. A seqüência de desastres coletivos como o sangrento movimento da Cabanagem e a ocorrência de outras epidemias locais somou-se à cólera. A presença da morte no cotidiano fez com que a Igreja católica pontificasse que o mal era uma espécie de punição sinistra aos pecaminosos, e apesar dos tempos de epidemia fluíam os populares para os templos religiosos, em busca de purificação. Também concentravam-se nos cemitérios para prestar as últimas homenagens aos seus mortos e, de certa forma, exorcizar a própria presença da morte.

Nesse cenário apocalíptico, Beltrão deteve-se na origem social daqueles que morriam. Contradizendo o jargão amplamente invocado pelas autoridades médico-administrativas e repetido na imprensa, a epidemia de cólera, como tantas outras, nada tinha de democrático, pois selecionava suas vítimas sobretudo entre os mais pobres, moradores nos bairros periféricos que, de regra, viviam em condições sub-humanas.

É importante ressaltar que, em uma região periférica em que a elite político-econômica comandava com mão-de-ferro as esferas pública e privada, os depoimentos pessoais que sobreviveram ao tempo apresentamse filtrados em favor dos dominantes. A imprensa paraense abriu pouco espaço para registrar os dramas daqueles que se acostumaram a calar. No entanto a memória popular manteve viva através do tempo a memória da epidemia de cólera de 1855-56, e quando a doença visitou novamente o Pará, na década passada, a autora soube perceber a importância disto. Na ausência de fontes documentais que melhor fizessem ouvir os grupos subalternos de meados do século XIX, Beltrão valorizou a voz contemporânea dos sofredores, detendo-se também nas informações quantitativas que, apesar de precárias, permitiram-lhe reiterar ter sido, percentualmente, a população miserável a pagar com mais vidas a visita da cólera do Oitocentos.

Com tal abordagem, o livro ganha uma dimensão abrangente e pautada por um teor humano comovente, envolvendo-nos da primeira à última página. Ao final de sua leitura também se percebe a importância de uma história recorrente que, ao (re)visitar o passado, contribui para o entendimento do presente: mais do que as teorias científicas vigentes no período das epidemias, o que torna drasticamente mais terrível a experiência coletiva com a peste é a continuidade da ausência de um compromisso mais claro e conseqüente do Estado para com a sociedade e das elites em relação à legião de desafortunados, circunstância implícita em todas as linhas do livro.

Os dois últimos parágrafos do escrito de Beltrão deixam bem claro a proposta e a indignação da autora sobre um momento bem próximo a todos nós: 
E os pobres continuam alvo de limpezas sociais. Em Belém, em Recife, em Paranaguá e em tantos outros lugares do Brasil, a cólera amedronta e nos faz dizer, ler, ver e ouvir: '.. o feirante era um cão sem dono. Não tinha família, dormia de favor no pátio de uma casa e vivia embriagado sempre que conseguia um tostão a mais. Higiene, nem pensar. Por isso, ela disse que não estranhou quando passou a noite de sexta feira de Carnaval pendurado de cócoras no muro do canal da rua São João e se desfazendo em fezes e vômitos. Vários foliões passaram pela rua e zombaram do feirante julgando que estivesse embriagado (trecho de uma matéria veiculada pelo jornal Folha de S. Paulo).

E Beltrão assim se despede de seu leitores: "Não estava embriagado! Era a cólera no final do século XX, em Recife, no ano da graça de 1992."

Não obstante seus méritos, o livro padece em vários trechos de uma escrita titubeante, dificultando a compreensão por parte do leitor, assim como notam-se algumas afirmações ou segmentos perfeitamente descartáveis do texto, tal como o que pontifica: "nem todos brancos mortos [durante a epidemia] eram ilustres" (p. 303). Ressalte-se, porém, que tais situações não chegam a ofuscar a importância do texto de Beltrão, que aflora como uma importante ferramenta para o entendimento das epidemias tanto do passado quanto do presente brasileiros.

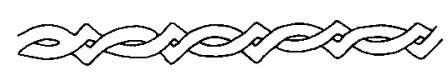

